\title{
A study on Select Solar Cell's Voltage Output at High Altitudes Using a Weather Balloon
}

\author{
Jalal M. Nawash, Rebecca Holzer, Rebekah Taylor and Jacob Bogeuschuetz \\ Department of Physics, University of Wisconsin - Whitewater
}

\begin{abstract}
The Voltage output of select solar cells was monitored as a function of altitude up to approximately 93,000 feet. A weather balloon was used to carry the solar cells to the required altitude. Two launches were accomplished to acquire data for analysis. Data collected also included the altitude, temperature and pressure. The voltage signal of the used solar cells depended largely on temperature. It was discovered that the voltage signal of the solar cells has a complex relationship with altitude. Temperature had a significant influence on the magnitude of the voltage signal at lower altitudes, but this influence may have declined at higher altitudes.
\end{abstract}

\section{Introduction}

Solar cells have become very popular in many applications, including providing electricity for houses, businesses and some cars. The solar cell industry has grown even faster in the past years due to the increasing demand for alternative sources of energy to fossil fuels. Solar energy is clean and lasts as long as the sun shines. Many researchers are dedicated to increasing the efficiency of solar cells for further applications. NASA's green aviation goals are to support fuel-efficient flight planning and to reduce aircraft fuel consumption, emissions, and noise. NASA's Ames Research Center has been working on reducing carbon footprint around the planet for decades. In addition to the environmental impact, switching to solar energy will have a positive economical influence. For example, the United States government has plans to fly light solar cell-powered drones at high altitudes for days at a time without the need to refuel. Doing this with a conventional plane would be expensive.

In this paper, a high altitude weather balloon was used to monitor the voltage output signal of solar cells at high altitudes. The efficiency is mostly calculated by dividing the output energy by the input energy. However, in this project, the changes in voltage output signal under a constant sunlight input is a sufficient indication of the efficiency changes. In recent years, there have been an increased number of investigations to address the effect of altitude on solar cells, but many more are still needed. Payloads carried by balloons can be equipped with devices and electronic equipment to record several types of data during the balloon ascent and descent. Temperature, pressure and other weather elements might have an effect on the efficiency. Two balloon launches were completed to collect data.

Hundreds of balloons are sent to the upper atmosphere every year around the planet [1] and weather balloons have been utilized in many different aspects of physics research. Some of this research has involved measuring the cosmic rays at high altitudes [2] and studying the various effects of weather on electrical and magnetic properties of high altitude ranges under several solar conditions $[3,4,5]$. Weather balloons were also employed to investigate the electric and magnetic fields generated in substorms [6]. In Wisconsin, Elijah High Altitude Balloon Payload Program launches 
balloons every year. One of their projects in recent years was to study mercury pollution at high altitudes [7]. Most investigators use balloons for weather studies, but few researchers have studied solar cell measurements [8].

Weather balloons are usually launched to near space altitudes, between 60,000 feet $-120,000$ feet. Most balloons carry a global positioning system (GPS) device to help locate the balloon payload after the balloon bursts and falls under the influence of gravity. Depending on the altitude the balloon ascends to, the trip up and down can take between one and three hours or more. Due to the rotational kinematics of earth, the landing location of the balloon will be to the east of the launching site. However this drift is also subjected to weather patterns and can range between 50 miles to 125 miles.

Photovoltaic (PV) cells or solar cells are mostly comprised of semiconductor crystals. Unlike conductors, semiconductors can conduct electricity only if the crystal was exposed to a certain voltage difference or provided with energy in a form of heat or light. What dictates this behavior is the energy band gap $\left(\mathrm{E}_{\mathrm{g}}\right)[9]$. Electrically, materials in general, have two energy bands separated by a gap. The lower band, where the electrons exist, is known as the valance band, while the upper band is called the conduction band. The energy separation between them can range from zero eV to a number of electron Volts. In conductors, the two bands overlap and $\mathrm{E}_{\mathrm{g}}=0 \mathrm{eV}$ which allows electrons to be free to conduct electricity. In semiconductors however, the separation between the two bands does not allow electrons to conduct electricity. The conducting electrons, which are found in the valance band, have to receive a quantized beam of energy that is equal to the energy gap $\mathrm{E}_{\mathrm{g}}$, as a result, the electrons jump from the valance band to the conduction band. When the electron becomes part of the conduction band population, it can move freely from one part of the crystal to another and thus conducts electricity. In semiconductors, $\mathrm{E}_{\mathrm{g}}$ is small, $0<\mathrm{E}_{\mathrm{g}}<3 \mathrm{eV}$ or $4 \mathrm{eV}$. Semiconductors can either be made out of pure crystals, such as those made from silicon $\left(\mathrm{E}_{\mathrm{g}}\right.$ at room temperature $=1.11 \mathrm{eV}[10])$ or Germanium $\left(\mathrm{E}_{\mathrm{g}}\right.$ at room temperature $\left.=0.67 \mathrm{eV}[11]\right)$. Mixing and synthesizing some materials or elements can also produce semiconductors. If $\mathrm{E}_{\mathrm{g}}>4$, it is known as an insulator and the material does not conduct electricity.

When electrons are mobilized from one region to another, they leave behind an excess of positive charge known as holes; this region is called "p". The region they end up in has an excess of negative charge is known as " $n$ ". A semiconductor that has these two regions forms what is known as the p-n junction diode. Since making the first solar cell in the late 1940s, the efficiency of single p-n junction crystalline silicon devices are now approaching the theoretical limiting efficiency of $37.7 \%$. However, the new multiple layer solar cells have a theoretical limit of $86 \%$ It is well known that the design and the shape of the solar cell platform have a noticeable effect on the efficiency at high altitudes [1].

\section{Procedure}

There are three main parts of the weather balloon; these parts are connected together via nonstretchable strong lightweight ropes. The upper part is a rubber balloon (Kaymont KCI TX3000 weather balloon) that is made out of latex or synthetic rubber (neoprene). This balloon was inflated by helium until it had the sufficient buoyant force required to lift off the payload. 
The second part of the weather balloon was the parachute, which was connected directly to the balloon using a rope and a U-shaped knot that was tightened by zip ties. The purpose of the parachute was to bring the payload back to the ground at a low and safe terminal velocity.

The third part was the payload itself, which was attached to the parachute using several ropes. The payload consisted of two Styrofoam boxes, one inside the other, to ensure that the fragile measuring instruments were protected. Had the payload landed on water, the extra Styrofoam also would have kept it afloat. The contents of the payload included two GoPro cameras to capture photos and videos. One camera was set to take pictures through the bottom of the box and the second one was placed on the side and recorded video footage. Two Track-it DataLoggers and one Spot GPS Tracker were mounted on the inside cover of the box. An Eagle Flight Computer, which measured weather elements and location (latitude and longitude) was placed on the cover outside the box. Some hand warmers were placed inside the box, which also contained the batteries to power instruments. Two PowerFilm MPT6-150 Solar Cells (3" X 4") were mounted on the outside part of the box cover. Both cells were placed inside a transparent plastic sealed top. The voltage signal from each cell was recorded independently. The temperature and pressure sensors were also place inside the sealed plastic top. See Figure 1.
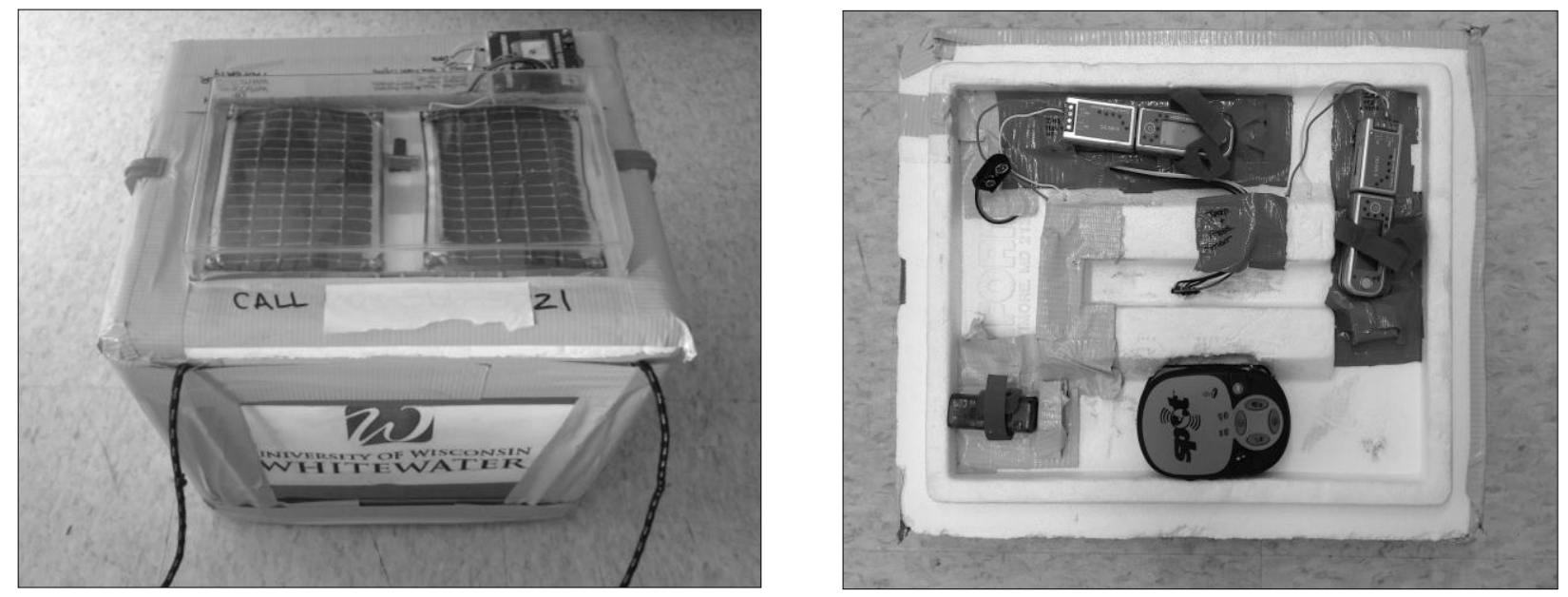

Figure 1. Photo of the payload and the cover of the box. The temperature and the pressure sensors were placed between the two solar cells under the sealed transparent cover (left). Some sensors, data loggers and the GPS were placed on the inside of the cover (right).

Prior to the launch, the measurement devices carried in the box were tested for proper function. Both launches used the same apparatus and design shown in Figure 1. The two launches were performed in Wisconsin on sunny days in August 2013 and April 2014. The choices for launch sites and dates were dictated mostly by weather. The flight predictor free website (predict.habhub.org) was chosen to trace the projected path of the balloon from launch to landing. The Spot GPS Tracker and Findmespot.com website were used to trace the actual trajectory of the balloon from launch to landing. See Figure 2. Once the launching location was chosen, the balloon was filled with Helium until it had sufficient force to lift up both the parachute and the payload. 


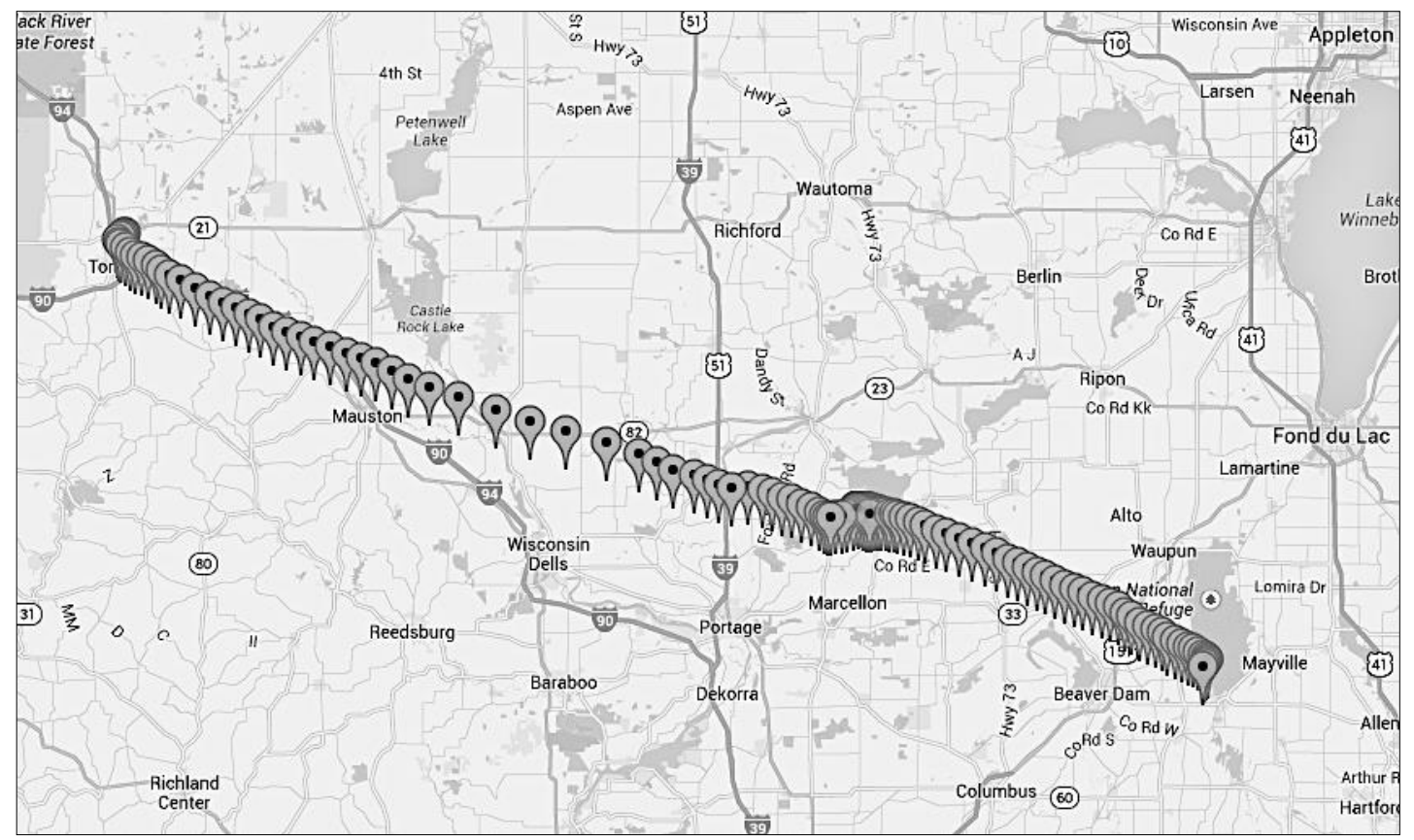

Figure 2. Actual trajectory of the second lunch was constructed by Spot GPS Tracker and Findmespot.com.

\section{Results and Analysis}

It was determined in the laboratory that these types of solar cells have voltage outputs that are highly dependent on temperature. As the temperature increased the voltage signal value decreased. The voltage signal was also tested on the ground when the cells are directly under the sunlight and when they are 3 feet within the shadow of a building. It was noticed that the voltage signal decreases by about $10 \%$ when it was in the shade. This test was necessary to understand how the voltage signal reacts when the solar cells come underneath the shaded areas created by the balloon/ parachute. Impact tests were also conducted to check the validity of the parachute when the load hit the ground.

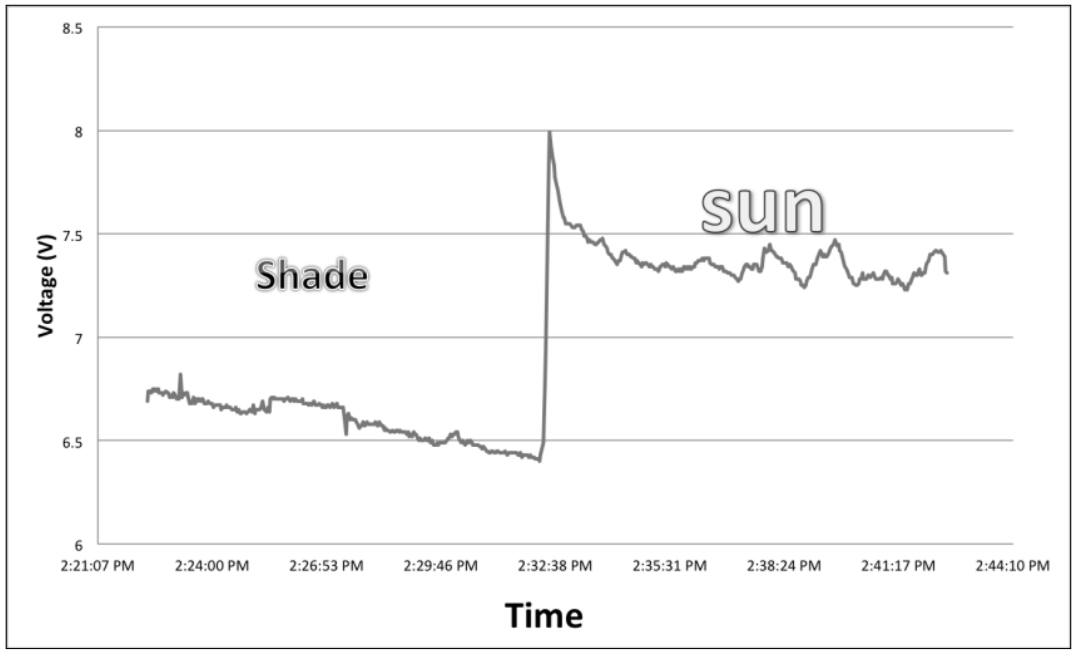

Figure 3. The solar cell voltage signal. The left side is in the shade and the right side is under the sun. 
The first launch, in which a lot of data was acquired and analyzed, was used as a learning experience to help perfect the second launch. No major problems were recorded for the first launch, however, the temperature sensor and the video camera failed

In the second launch, temperature, pressure, altitude, voltage signals and other data were collected and analyzed. Figure 4 (left) shows the pressure for the entire flight. From this graph, it was clear to see that the ascending trip took almost twice the time of the descending one (less than an hour). Figure 4 (right) shows the temperature inside the sealed transparent chamber, where the solar cells were, as a function of time for a complete flight. It appeared that the temperature increased to a maximum value of $73{ }^{\circ} \mathrm{C}\left(\sim 163{ }^{\circ} \mathrm{F}\right)$. This unexpected high temperature might have resulted from the combination of the hand warmers that were placed inside the box and the greenhouse effect created by the sun's rays on the tightly sealed small transparent chamber. Both graphs started counting time 0.75 hours before the launch and kept recording till about 0.25 hours after landing.
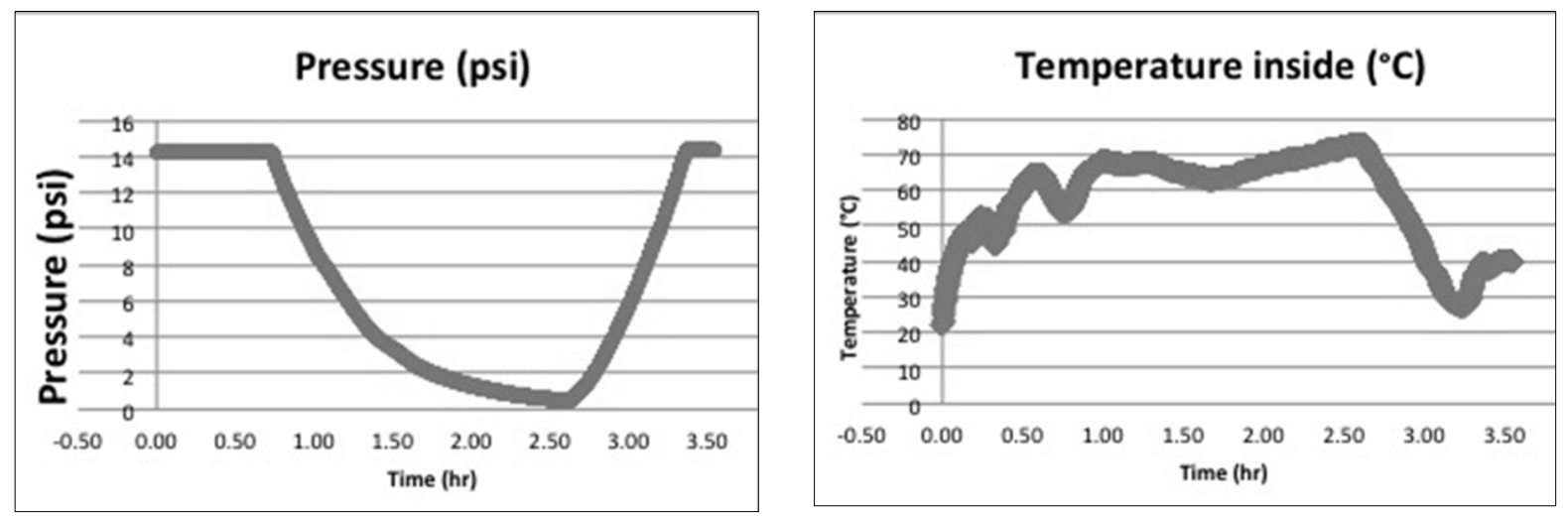

Figure 4. Pressure (left) and temperature (right) as a function of time for the complete trip.

In Figures 5 and 6 , graphs of the temperature $\left({ }^{\circ} \mathrm{F}\right)$ and voltage (V) for the ascending trip only are shown as a function of time. These two graphs are to the same scale. Both the temperature and voltage signals exhibited a uniform pattern. As was expected from the tests performed on the solar cells on the ground, it was realized that the voltage signal decreased when the temperature increased.

From the graphs and at the very start of the ascending trip, the voltage signal increased slightly as a response to the decrease in temperature, which was expected. This occurred immediately after the launch and at a very low altitude. During this period, the maximum voltage output was recorded for the whole trip. Then, as the temperature increased to $150^{\circ} \mathrm{F}$, the signal dropped accordingly. The temperature increase continued, but at a slower rate, and output signal responded slightly to this change by slowing down the decrease rate, as can be seen at about 15,000 ft. After this point and between 0.25 hours to 0.65 hours, the temperature made a slight decrease then returned to the previous level. Although this temperature fluctuation can be seen affecting the voltage signal between $15,000 \mathrm{ft}$. to $21,000 \mathrm{ft}$., the slight change (in the voltage signal) in this altitude range could also be the result of the slower temperature increase rate that occurred earlier. 


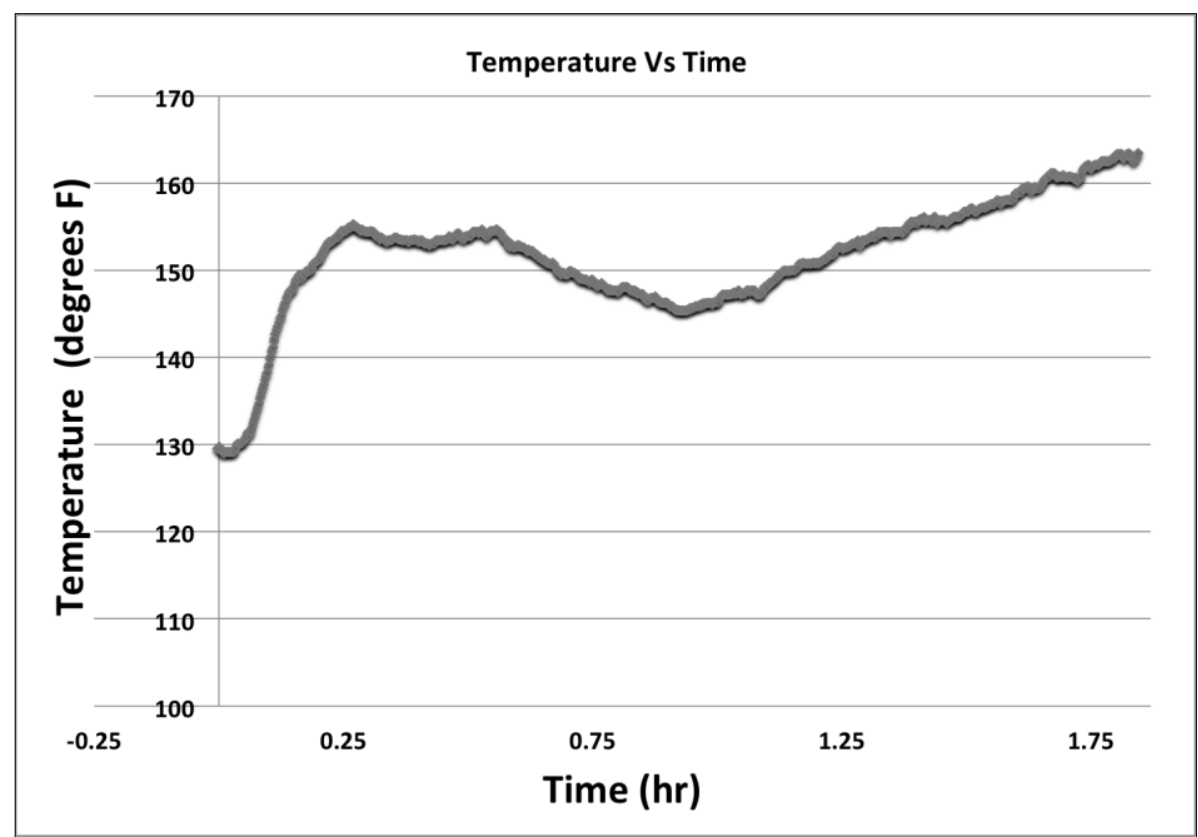

Figure 5. Temperature $\left({ }^{\circ} \mathrm{F}\right)$ for the ascending trip only as a function of time.

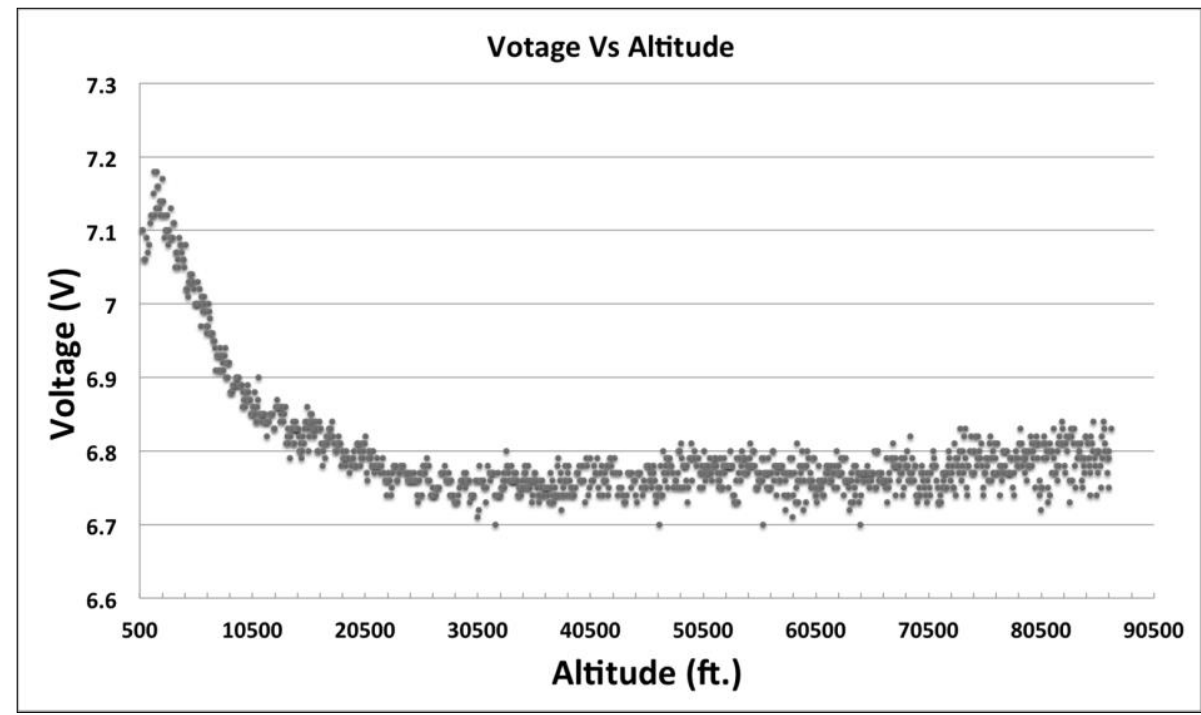

Figure 6. Voltage for the ascending trip only as a function of time. These two last figures were to the same scale.

Finally, at the long range defined between 0.65 hours to 1.87 hours, the temperature decreased to $145^{\circ} \mathrm{F}$ after one hour (of the flight time) then gradually increased to $163^{\circ} \mathrm{F}$. In Figure 6 , this is shown in altitudes above $25,000 \mathrm{ft}$. In this full region although the voltage signal was slightly affected, it is a far less reaction than those seen at lower altitudes. For example, the temperature increased by a large percentage between the time one hour and 1.87 hours and the signal barely changed. The indirect relationship between temperature and voltage seemed to fade away at those altitudes. One explanation to that is the rate at which the voltage signal increased as altitude increased was the same rate it has decreased due to temperature's increase, this combined effect forced the voltage signal to plateau when it should decrease. This leads to the conclusion that voltage output signal had increased when the balloon was at an altitude above 45,000 ft. Another 
explanation is that above $45,000 \mathrm{ft}$., temperature fluctuations do not have an influence on the voltage signal for these types of solar cells.

The voltage output signal was also analyzed during the ascending part of the flight. See Figure 7. Both voltage (stars) and temperature (solid line) displayed a uniform pattern where temperature and voltage are in an ideal indirect relationship.

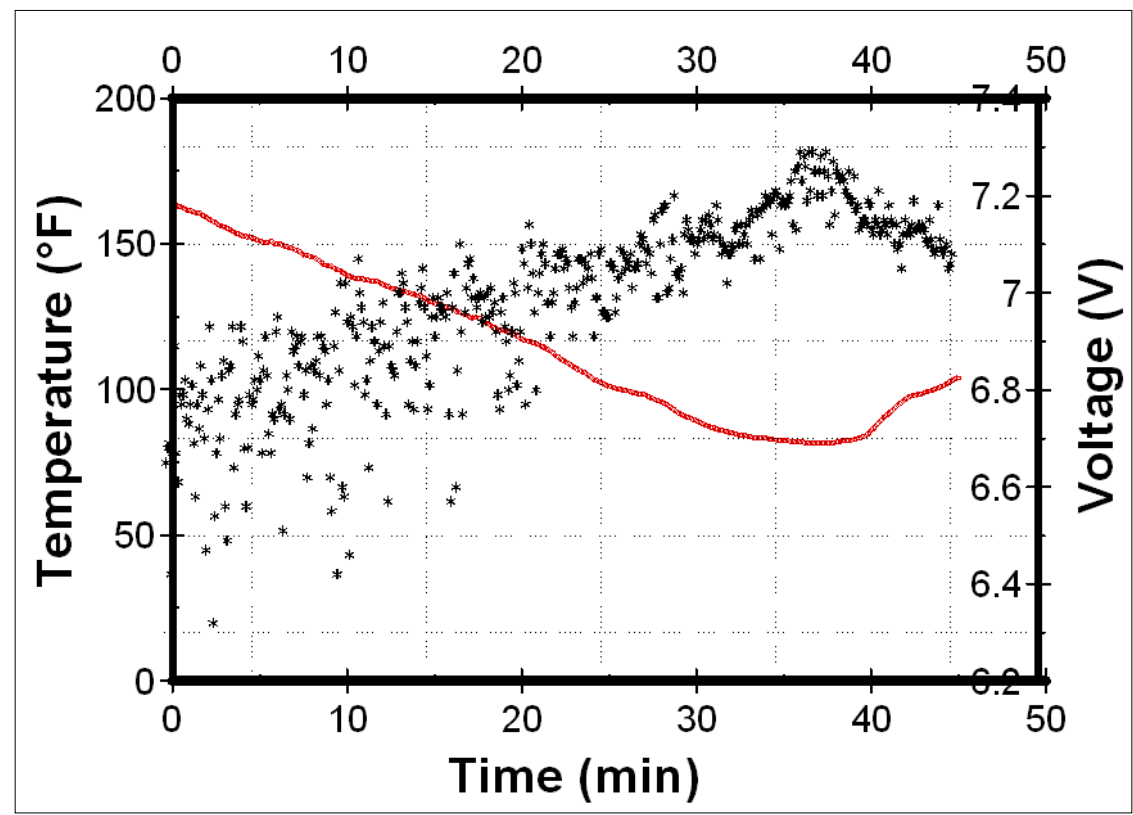

Figure 7. A plot of voltage and temperature (solid line) during descend, as a function of arbitrary unit.

Finally, a summary of the two launches is shown in Table 1.

\begin{tabular}{|c|c|c|}
\hline & Launch \# 1 & Launch \#2 \\
\hline Date & August 28, 2013 & April 26, 2014 \\
\hline $\begin{array}{c}\text { Maximum Height } \\
\text { (ft.) }\end{array}$ & 93200 & 80215 \\
\hline $\begin{array}{c}\text { Length of the flight } \\
\text { (hr.) }\end{array}$ & 2.8 & 2.6 \\
\hline $\begin{array}{c}\text { Max voltage signal } \\
\text { (regardless of } \\
\text { temperature) }\end{array}$ & $\sim 34000 \mathrm{ft.}$ & $\sim 1000 \mathrm{ft.}$ \\
\hline \multirow{2}{*}{ Notes } & $\begin{array}{c}\text { Video and } \\
\text { temperature sensor } \\
\text { did not function }\end{array}$ & $\begin{array}{c}\text { Temperature went up } \\
\text { more that expected }\end{array}$ \\
\cline { 2 - 3 } & $\begin{array}{c}\text { Pictures were } \\
\text { captured when } \\
\text { Balloon popped }\end{array}$ & $\begin{array}{c}\text { Balloon popped after } \\
\text { cameras died }\end{array}$ \\
\hline
\end{tabular}

Table 1. A summary of the two launches. 


\section{Conclusion}

The output voltage signals of select solar cells were monitored and recorded as a function of altitude using a weather balloon. It was not clear if signal was influenced by the change in altitude at lower elevations, as the influence of temperature on the efficiency is very evident, as discussed previously. It was also found that the signal plateaued above 45,000 ft. This could be the result of increasing temperature and altitude. But since an increase in temperature was proven to cause the voltage signal to decrease, a flattened signal output might be explained as a result of an increasing voltage signal.

Future work will include using more than one type of solar cells to obtain a universal conclusion. If a sealed transparent chamber should be used to enclose solar cells, then a temperature regulator to keep the temperature constant inside is a must. This will lead to more reliable data to better understand how the voltage signal changes as a function of altitude, especially above 45,000 feet.

\section{Acknowledgments}

The authors would like to thank Wisconsin Space Grant Consortium (WSGC) for funding this project. We are also grateful for the College of Letters and Sciences and the Office of Research and Sponsored Programs at University of Wisconsin - Whitewater for funding and supporting this work. Many thanks and appreciation go to students Alexander Neumann and Charles Simonet who started working on this project long before it was funded.

\section{References}

[1] G Romeo, G Frulla, and E Cestino, Design of a high-altitude long-endurance solar-powered unmanned air vehicle for multi-payload and operations, Special Issue Paper 199.

[2] G. Basini and M. Ricci, Balloon measurements of cosmic ray muon spectra in the atmosphere along with those of primary protons and helium nuclei over midlatitude, Phys. Rev. D 60, 1999.

[3] H. S. Hopfield and Tropospheric, Effect on Electromagnetically Measured Range: Prediction from Surface Weather Data, Radio Science Vol. 6, NO. 3, 1971,

[4] R. H. Holzworth, High latitude stratospheric electrical measurements in fair and foul weather under various solar conditions, Journal of Atmospheric and Terrestrial Physics, Volume 43, Issue $\underline{11}, 1981$.

[5] J.J. López-Moreno, G.J. Molina-Cuberos, R. Rodrigo, M. Hamelin, and K. Schwingenschuh, Polar ionic conductivity profile in fair weather conditions: Terrestrial test of the Huygens/HasiPWA instrument aboard the Comas Sola balloon, Journal of Atmospheric and Solar-Terrestrial Physics, Volume 63, Issue 18, 2001.

[6] T. J. Rosenberg, J. R. Benbrook, D. Detrick, D. L. Matthews, M. J. Rycroft, M. A. Saunders, W. R. Sheldon, and E. A. Bering, Electric Fields, Electron Precipitation, and VLF Radiation During a Simultaneous Magnetospheric Substorm and Atmospheric Thunderstorm, Journal of Geophysical Research, Vol. 85, No. A1, 1980. 
[7] http://www.uwgb.edu/WSGC/default.aspx

[8] F. W. Sarles, W. C. Haase, and P. F. McKenzie, Balloon Flight Instrumentation for Solar Cell Measurements, Rev. Sci. Instrum. 42, 1971.

[9] W. D. Callister and D. G. Rethwisch, Materials science and engineering: an introduction, John Wiley \& Sons, 2009.

[10] J. D. Holmes, K. P. Johnston, R. C. Doty, B. A. Korgel, Control of Thickness and Orientation of Solution-Grown Silicon Nanowires Science, Vol. 287 no. 5457, 2000.

[11] B. G. Streetman and S. Banerjee Solid State electronic Devices (5th ed.), New Jersey: Prentice Hall. p. 524. (2000). 